J. Clin. Chem. Clin. Biochem.

Vol. 25, 1987, pp. 683-687

(C) 1987 Walter de Gruyter \& Co. Berlin - New York

\title{
Immunoturbidimetric Assay for the Determination of Microalbuminuria Using the Hitachi Analyser
}

\author{
By M. M. C. Landgraf-Leurs, E. Modi, K. Horn and R. Landgraf \\ Medizinische Klinik Innenstadt der Universität München, München FRG
}

(Received March 18/August 7, 1987)

Summary: A sensitive and specific immunoturbidimetric method is described for the determination of low concentrations of urinary albumin using a Hitachi 704 or 705 analyser. The sensitivity was $1 \mathrm{mg} / \mathrm{l}$ and the precision attained was good (CV 15\%,7\% and $6 \%$ for low, medium and higher albumin concentrations). The assay was used to determine urinary albumin excretion rates in healthy controls $(<15 \mu \mathrm{g} / \mathrm{min})$ and in type I diabetics. Since microalbuminuria $(30-200 \mu \mathrm{g} / \mathrm{min})$ seems to be a good predictor for the development of diabetic nephropathy and other late diabetic complications, this assay is suitable for the necessary screening and follow-up of diabetic nephropathy. In contrast to RIA methods, no radioactive tracers are needed.

\section{Introduction}

Nephropathy is one of the severe late complications in diabetes mellitus, which results in a high morbidity up to haemodialysis and a high mortality. By the time renal function tests become abnormal and albuminuria is detectable by standard clinical tests, diabetic nephropathy is irreverșible (1). However, glycaemic and blood pressure control $(1,2)$ might retard or arrest the progression of diabetic nephropathy in the state of microalbuminuria $(3,4)$. The degree of microalbuminuria is also predictive of the progression to clinical proteinuria in type I $(5-7)$ and in type II (8) diabetics. Furthermore the percentage of patients with low abnormal albumin excretion rates (30$200 \mu \mathrm{g} / \mathrm{min}$ ) that have retinopathy is higher than in normal albuminuric patients $(<20-30 \mu \mathrm{g} / \mathrm{min})$ and the risk for the development of proliferative retinopathy is high $(6,9)$.

Radioimmunoassays have been developed to detect microalbuminuria $(10,11)$ with the obvious disadvantage of radioactive tracers. Low concentrations of albumin can also be measured by radial-immunodiffusion $(7,12)$. Immunoturbidimetric methods for the measurement of albumin have been published $(4,13$, 14). We present the adaptation of an immunoturbidi- metric method for the determination of low concentrations of albumin in urine to a Hitachi analyser type 704 or 705 , that enables routine measurements of urine samples in a short time (180 samples per hour) at low cost.

\section{Materials and Methods}

\section{Reagents}

Polyethyleneglycol 6000 (PEG) was obtained from MerckSchuchardt, Hohenbrunn, FRG. The assay buffer contained per litre: $50 \mathrm{mmol}$ phosphate, $100 \mathrm{mmol} \mathrm{NaCl}, 40 \mathrm{~g}$ PEG 6000 and $1 \mathrm{~g} \mathrm{NaN}_{3}$. The $\mathrm{pH}$ was adjusted to 7.4. In the following this buffer is referred to as PBS-PEG. Purified, lyophilized human albumin was purchased from Behringwerke AG, Marburg, FRG. Solutions containing 2.5, 5, 10, 20, 40 and $80 \mathrm{mg} / 1$ human albumin were prepared in the buffer described above. An anti-human-albumin-antibody (A119) was obtained from Dakopatts, Hamburg, FRG. The antibody was prediluted in buffer and centrifuged at $3000 \mathrm{~g}$ for $15 \mathrm{~min}$ before use.

All other reagents were of analytical grade.

\section{Turbidimetric measurement of albumin}

Initially a modification of published methods $(4,13,14)$ using an Eppendorf Photometer with glass microcuvettes was used. The method was then adapted to an Hitachi analyser type 704, frequently used in clinical chemistry. Twenty microlitres of the 
albumin-containing solution or of the urine sample were mixed with $330 \mu$ PBS-PEG and preincubated for 5 minutes at $30^{\circ} \mathrm{C}$. Then $50 \mu$ l of diluted antibody solution were added, followed by another 5 minutes incubation at $30^{\circ} \mathrm{C}$. The absorbance was measured bichromatically at wavelengths 340 and $700 \mathrm{~nm}$.

\section{Radioimmunoassay of albumin}

Fourty two urine probes were measured with a commercially available radioimmunoassay (Pharmacia, Uppsala, Schweden).

\section{Urine collection}

Thirty five healthy women and 30 healthy men (mean age 33 years, range $17-54$ years), as well as 15 diabetic men and 14 diabetic women (mean age 33 years, range 14-76 years) provided overnight urine, using the following procedure. They passed urine immediately before going to bed, discarded this sample and recorded the time. The urine passed during the night and immediately after they got up in the morning was collected without preservative, the volume measured and the time recorded.

Furthermore, 3 healthy men and 6 healthy women (mean age 28 years, range $21-46$ years) as well as 14 diabetic men and 4 diabetic women (mean age 33 years, range 19-64 years) collected urine:over 24 hours during normal daily activities without extreme muscular exercise.

Urine samples were frozen at $-20^{\circ} \mathrm{C}$. Before the assay the samples were centrifuged for $2 \mathrm{~min}$ at $9000 \mathrm{~g}$ in an Eppendorf centrifuge 3200 .

\section{Results}

Figure 1 (left) depicts the absorbance changes with time at different albumin concentrations $(5-80$ $\mathrm{mg} / \mathrm{l})$, measured with an Hitachi 704. After addition of the anti-albumin-antibody the absorbance increases rapidly and levels off after about 120 seconds. There is a linear relationship between the absorbance and the albumin concentration at the plateau level (fig. 1 right). The curves were not different if albumin was added to PBS-PEG or to albumin-free urine. Albumin-containing urines show the same kinetics of absorbance as the albumin-containing buffer solutions (not shown). Therefore albumin in urine can easily be determined by comparison with albumin standards dissolved in buffer.

The mean values of standard albumin concentrations obtained in ten different assays on the Hitachi 704 are depicted in figure 2.

The dilution curve of a urine containing $76 \mathrm{mg} / \mathrm{l}$ albumin fell exactly on the albumin standard curve, irrespective of the dilution medium (PBS-PEG or albumin-free urine; fig. 3). Up to $80 \mathrm{mg} / \mathrm{l}$ albumin the absorbance changes were independent of the final dilution of the antialbumin antibody $(1: 40,1: 80$ or $1: 160)$. However, at higher albumin concentrations a loss of linearity was observed and false low values were measured, especially when high antibody dilutions were used (fig. 4). Therefore the first urine sample of each patient was estimated undiluted and at a 1:2 dilution. During follow-up of the diabetic patients with albuminuria under $100 \mathrm{mg} / \mathrm{l}$, urine was estimated undiluted; for concentrations above 100 $\mathrm{mg} / \mathrm{l}$ the urine was diluted. A rather high antibody concentration $(1: 40)$ was used to assure that the antibody was present in excess.
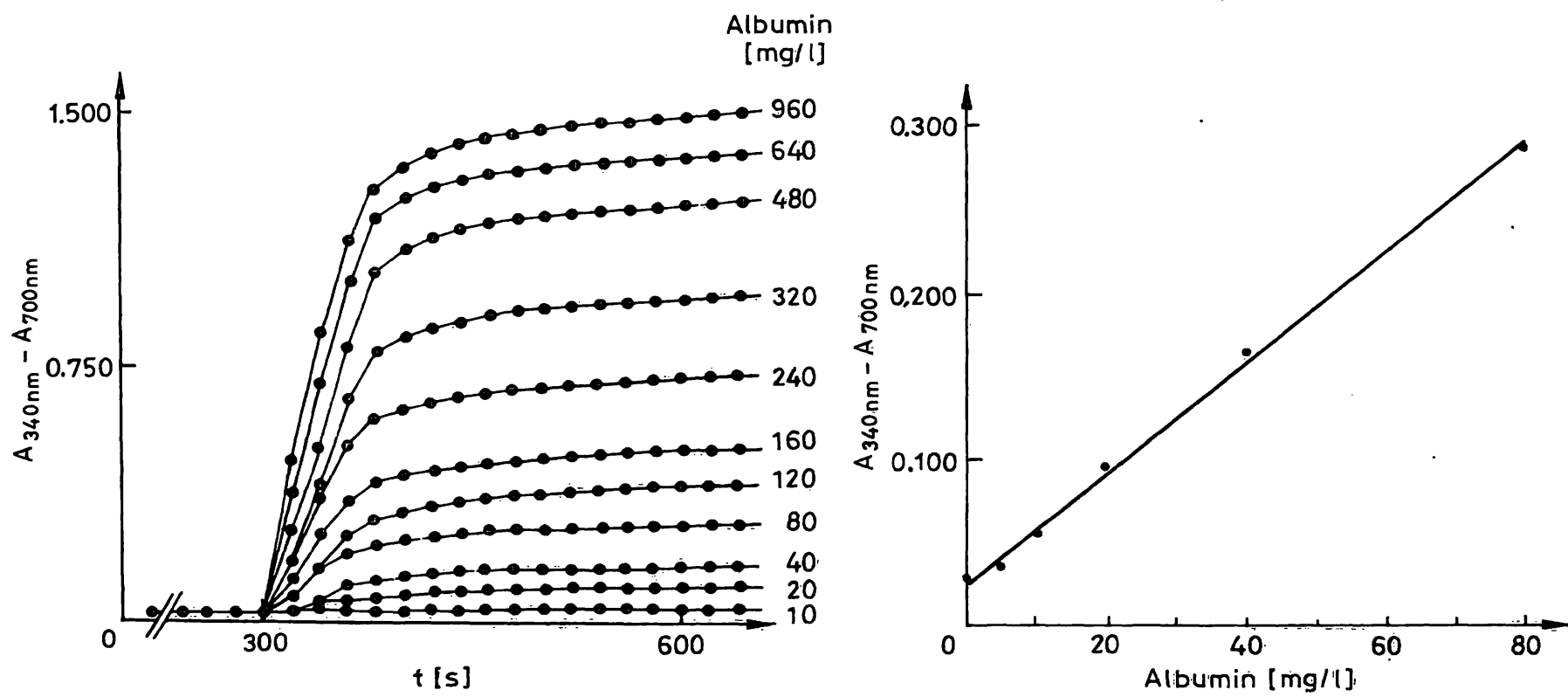

Fig. 1. Left: Absorbance changes with time at different albumin concentrations. The absorbance of the albumin-containing solutions were measured with an Hitachi analyser type 704. After a preincubation of 300 seconds anti-albumin antibody was added and the absorbance recorded at 20 seconds intervals.

Right: The absorbance values measured at 300 seconds after addition of the antibody were plotted against the albumin concentrations. 


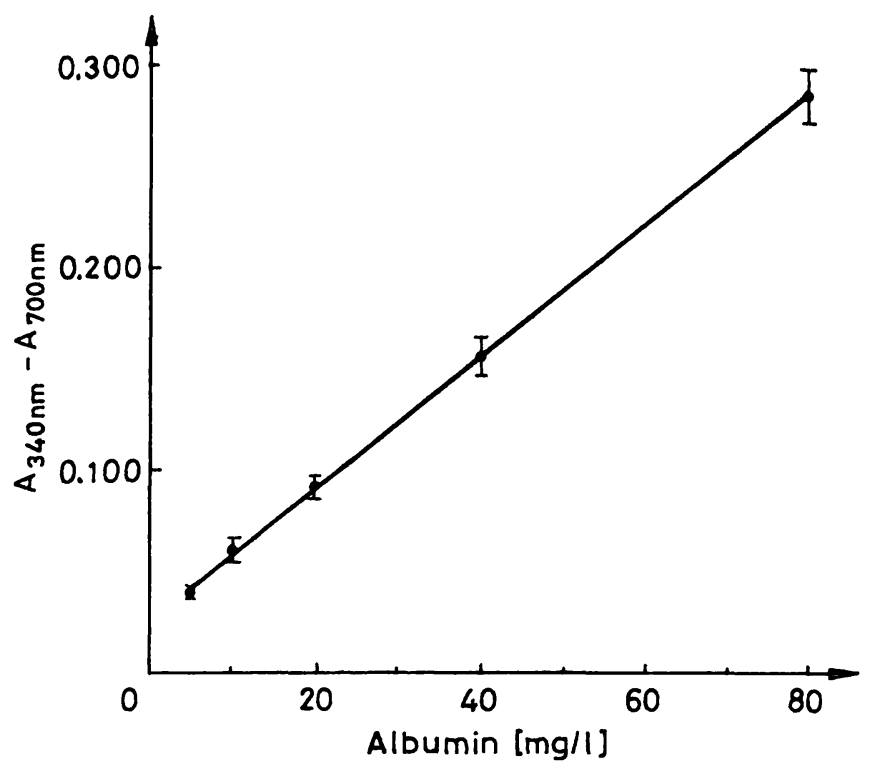

Fig. 2. Albumin concentrations in standard albumin solutions are plotted against the differences of the absorbance at $340 \mathrm{~nm}$ and $700 \mathrm{~nm}$, measured 300 seconds after addition of the antibody solution $(1: 40)$. The curve represents the mean \pm SEM of ten different assays.

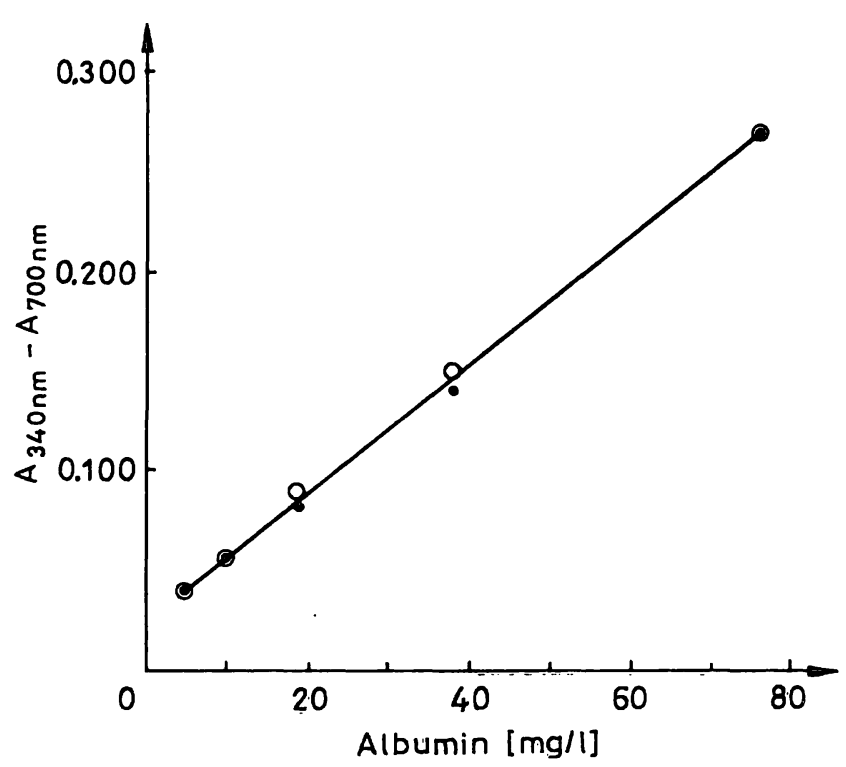

Fig. 3. Dilution curve of an albumin-containing urine. The dilution medium was PBS-PEG (closed symbols) or albumin-free urine (open symbols). The solid line represents the curve obtained with standard albumin solutions.

The intra- and interasssay vạriations of ten determinations of three urine samples with different intrinsic albumin concentrations are depicted in table 1 .

The validity of the turbidimetric assay was tested against a radioimmunoassay.

The values analysed by the immunoturbidimetric method were on average somewhat higher than those measured by RIA.

There was a highly significant correlation between the values measured by the radioimmunoassay and the turbidimetric method $(\mathrm{r}=0.983 ; \mathrm{p}<0.001$; fig. 5).

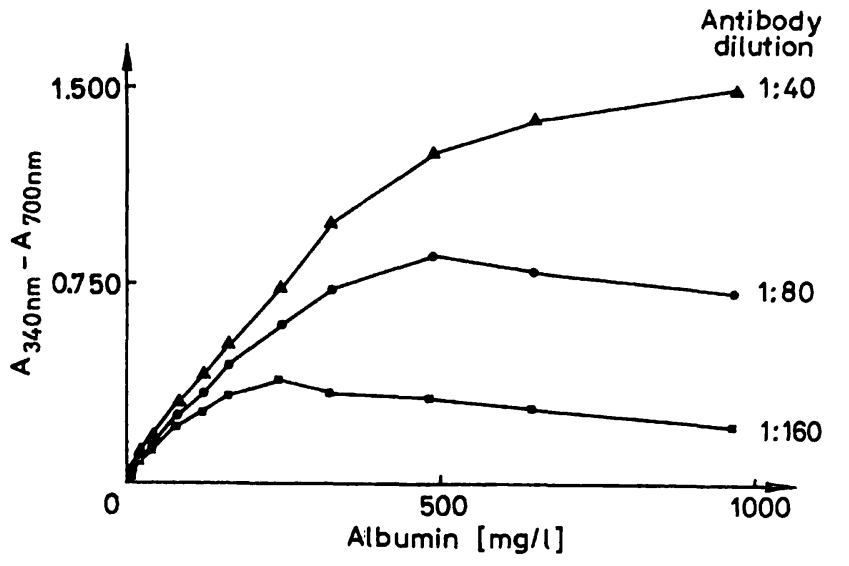

Fig. 4. The difference of the absorbance at $340 \mathrm{~nm}$ and 700 $\mathrm{nm}$ of albumin standard solutions measured 300 seconds after the addition of different antibody dilutions is plotted against the albumin concentrations. The final dilutions of the antialbumin-antibody were $1: 160$ (घ), 1:80(๑), and 1:40 (A).

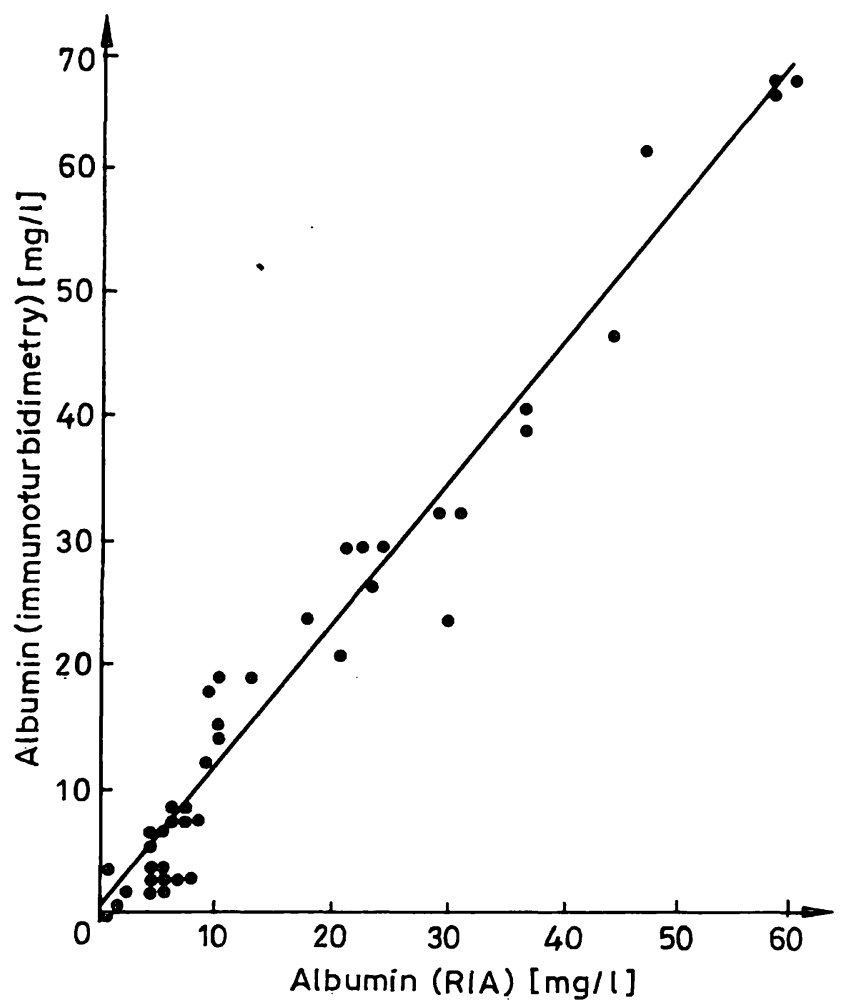

Fig. 5. Comparișon of albumin concentration values measured by radioimmunoassay and turbidimetric assay in 42 urine samples:

$r=0.983 ; \mathrm{p}<0.001$.

Tab. 1. Intra- and inter-assay variation of ten immuno-turbidimetric measurements of albumin in urine on the Hitachi 704.

\begin{tabular}{lclr}
\hline Variation & \multicolumn{3}{l}{ Albumin concentration } \\
\cline { 2 - 4 } & $\begin{array}{l}\text { mean } \\
(\mathrm{mg} / \mathrm{l})\end{array}$ & $\begin{array}{l}\mathrm{SD} \\
(\mathrm{mg} / \mathrm{l})\end{array}$ & $\begin{array}{l}\mathrm{CV} \\
(\%)\end{array}$ \\
\hline Intra-assay & 3.0 & 0.0 & 0.0 \\
& 44.2 & 0.6 & 1.4 \\
& 74.0 & 1.8 & 2.5 \\
Inter-assay & 3.2 & 0.4 & 13.0 \\
& 43.0 & 3.0 & 7.0 \\
& 71.4 & 4.2 & 5.9 \\
\hline
\end{tabular}


Albumin measurements in urine of healthy and diabetic persons

The mean albumin excretion rates, measured in overnight urines of 65 healthy persons was $4.7 \mu \mathrm{g} / \mathrm{min}$ \pm 5.1 (mean \pm S. D.), the two S. D. range being 0 $14.9 \mu \mathrm{g} / \mathrm{min}$. The albumin excretion in urines collected by nine control persons over 24 hours were well within this range $(3.2 \pm 1.8 \mu \mathrm{g} / \mathrm{min}$, range $0-5$ $\mu \mathrm{g} / \mathrm{min}$ ). There was no significant difference in the overnight albumin excretion rates in males and females (males $4.5 \pm 3.5 \mu \mathrm{g} / \mathrm{min} \mathrm{n}=30$, females: 4.9 $\pm 6.3 \mu \mathrm{g} / \mathrm{min}, \mathrm{n}=35$ ).

Out of 29 diabetic patients, 19 had overnight albumin excretion rates within the normal range, 10 ranged from 91 to $3850 \mu \mathrm{g} / \mathrm{min}$, and five of them were negative by albustix.

Eighteen type I diabetic patients provided urine over 24 hours. Fourteen diabetics had albumin excretion rates below $20 \mu \mathrm{g} / \mathrm{min}$ and the three others were 544 , 636 and $1198 \mu \mathrm{g} / \mathrm{min}$. The last three were also positive by albustix.

Fourteen of these patients collected 24-hour urine seven times at two-week intervals. The mean values of these seven samples of each patient are shown in table 2. This table demonstrates the well known variance in albumin excretion rates, also within the normal range. Three patients had low but pathological values $(20-200 \mu \mathrm{g} / \mathrm{min})$ at least on one occasion, which underlines the necessity of repeated examinations at short intervals in these cases before the diagnosis of microalbuminuria can be confirmed. It furthermore enables intensified control, which might

Tab. 2. Mean of seven albumin excretion rates in 14 diabetic patients.

\begin{tabular}{cccc}
\hline Patient & $\begin{array}{l}\text { Mean } \\
/ \mu \mathrm{g} / \mathrm{min})\end{array}$ & $\begin{array}{l}\text { S. D. } \\
(\mu \mathrm{g} / \mathrm{min})\end{array}$ & $\begin{array}{l}\text { Range } \\
(\mu \mathrm{g} / \mathrm{min})\end{array}$ \\
\hline 1 & 0.4 & 0.8 & $0-2$ \\
2 & 2 & 1 & $0-3$ \\
3 & 2 & 2 & $0-6$ \\
4 & 2 & 2 & $0-6$ \\
5 & 2 & 2 & $0-6$ \\
6 & 2 & 6 & $0-15$ \\
7 & 4 & 2 & $1-8$ \\
8 & 5 & 4 & $0-10$ \\
9 & 6 & 3 & $1-10$ \\
10 & 7 & 5 & $3-17$ \\
11 & 8 & 11 & $2-30$ \\
12 & 11 & 9 & $3-22$ \\
13 & 829 & 173 & $636-1187$ \\
14 & 1338 & 353 & $771-1969$ \\
\hline
\end{tabular}

prevent an increase in albumin excretion rates as the result of irreversible diabetic nephropathy.

\section{Discussion}

The adaptation of an immunoturbidimetric method for measuring albumin to the Hitachi analyser, an apparatus used in many laboratories for routine clinical chemistry, provides a rapid and inexpensive method for the measurement of albumin in urine below levels detectable by standard laboratory methods. In addition, no radioactive isotopes are needed.

Using an Hitachi 704 we established an upper limit of normal for the albumin excretion rate of $15 \mu \mathrm{g} /$ min (mean $\pm 2 \mathrm{~S}$. D.; $\mathbf{n}=65$ ) which is comparable to the values in the literature using RIA methods or radial immunodiffusion $(6,7,15)$.

The sensitivity of the assay was $1 \mathrm{mg} / \mathrm{l}$, the interassay coefficients of variation at $3 \mathrm{mg} / 1,40 \mathrm{mg} / 1$ and 70 $\mathrm{mg} / \mathrm{l}$ albumin were $13 \%, 7 \%$ and $6 \%$ respectively. Therefore the method is sensitive and precise enough to measure the low albumin concentrations present in normal urine and in diabetic microalbuminuria. The fast assay time, low cost and good precision makes this the method of choice for routine albumin determination.

Since the values found in control and diabetic persons are comparable with those published $(2,4-9,15-$ 18), this immunoturbidimetric assay is suitable for the screening and follow up of early diabetic nephropathy. This is important since the degree of microalbuminuria seems to be a good predictor for clinical nephropathy and retinopathy (5-9). Since a small increase in microalbuminuria might be reversible by strict blood glucose and blood pressure control $(3,4)$ a routine check-up for microalbuminuria every three months seems to be advisable (16). When values between 20 and $200 \mu \mathrm{g} / \mathrm{min}$ albumin excretion rate are found, two controls at short time intervals are necessary to confirm the diagnosis of microalbuminuria.

Timed overnight urine collection was chosen as a convenient and practicable method for most patients. It avoids the effects of posture and different degrees of physical exercise on albuminuria, especially seen in diabetics $(15,17,18)$, although not observed in the small number of diabetics presented in this communication. 


\section{References}

1. Mogensen, C. E. (1976) Scand. J. Clin. Lab. Invest. 38, $383-388$.

2. Parving, H. H., Smidt, U. M., Andersen, A. R. \& Svendsen, P. A. (1983) Lancet $I, 1175-1178$.

3. Viberti, G. C., Pickup, J. C., Jarrett, R. J. \& Keen, H. (1979) N. Engl. J. Med. 300, 638-641.

4. Rowe, D. J. F., Hayward, M., Bagga, H. \& Betts, P. (1984) Br. Med. J. 289, 957-959.

5. Viberti, G. C., Jarrett, R. J., Mahmud, U., Hill, J. D., Argyropoulos, A. \& Keen, H. (1982) Lancet $I, 1430-1432$.

6. Mogensen, C. E. \& Christensen, C. K. (1984) N. Engl. J. Med. 311, 89-93.

7. Mathiesen, E. R., Oxenboll, B., Johansen, K., Svendsen, P. A. \& Deckert, T. (1984) 26, 406-410.

8. Mogensen, C. E. (1984) N. Engl. J. Med. 310, 356-360.

9. Barnett, A. H., Dallinger, K., Jennings, P., Fletcher, J. \& Odugbesan, O. (1985) Lancet $I, 53-54$.

10. Keen, H. \& Chlouverakis, C. (1963) Lancet II, 913-914.

11. Miles, D. W., Mogensen, C. E. \& Gundersen, H. J. G. (1970) Scand. J. Clin. Lab. Invest. 26, 5-11.

12. Maneini, G., Carbonara, A. O. \& Heremans, J. F. (1965) Immunochemistry 2, 235-254.

13. Spencer, K. \& Price, C. P. (1979) Clin. Chim. Acta 95, $263-276$.

14. Teppo, A.-M. (1982) Clin. Chem. 28, 1359-1361.

15. Feldt-Rasmussen, B., Baker, L. \& Deckert, T. (1985) Diabetologia 28, 389-396.

16. Mogensen, C. E. \& Christensen, C. K. (1985) Nieren- und Hochdruckkrankheiten $8,352-360$.

17. Viberti, G. C., Jarrett, R. J., McCartney, M. \& Keen, H. (1978) Diabetologia 14, 293-300.

18. Cowell, C. T., Rogers, S. \& Silink, M. (1986) Diabetologia 29, 97-99.

Dr. med. M. M. C. Landgraf-Leurs Medizinische Klinik Innenstadt der Universität München Ziemssenstr. 1

D-8000 München 2 
